\title{
A Model to Solve Maintenance Problem of Zambezi River
}

\author{
Yun Zhang \\ Department of Electronic and Communication Engineering, North China Electric Power University, \\ Baoding 071003, Hebei, China \\ 1034044638@qq.com
}

Keywords: the Kariba Dam, genetic algorithm, multi-stage dams.

\begin{abstract}
This paper provides a model to solve maintenance problem of Zambezi River. With analyzing multi-stage dams and applying genetic algorithm, the model provides a new system of dams that have the same overall water management capabilities as the existing Kariba Dam while having the same or greater levels of protection and water management options for Lake Kariba that are in place with the existing dam.
\end{abstract}

\section{Introduction}

The Kariba Dam on the Zambezi River is one of the biggest dams in Africa. The volume of the sedimentation of the Kariba Dam is $300,000,000^{[1]}$ tons per annum. And the unit average amount of comprehensive cultivated land loss is $8,050,313.550^{[2]} \mathrm{USD} / \mathrm{km}^{2}$. Its construction was controversial, and a 2015 report by the Institute of Risk Management of South Africa released a warning that the dam is in dire need of maintenance. A number of options are available to the Zambezi River Authority (ZRA) that might deal with the situation. One of the solutions is removing the Kariba Dam and replacing it with a series of ten to twenty smaller dams along the Zambezi River.

To find the optimum number of the small dams and location of each dam, the model has four restrictions including sedimentation, generated power amount, construction cost and regulating storage capacity. Then use the four restrictions to make the model and calculate the optimum number of the dams and figure out the location by using genetic algorithm.

The model is a strategy for modulating the water flow with a new multiple dam system, which provides a reasonable balance between safety and costs. Apart from ensuring present or predicted normal water cycles, the model provides guidance to the ZRA managers that will properly handle emergency water flow situations. Besides, the locations and lengths of time that different areas of the Zambezi River and the most detrimental effects of the extreme conditions are analyzed.

\section{Restrictions of The Solution}

To analyze this solution, figuring out how many dams needed and where to build them is required. According to the data provided by Wikipedia, the location and number of the small dams are relevant to four main factors--sedimentation, amount of generated power, construction cost and regulating storage capacity. This paper begins with enumerate four models about the factors, and then analyzes the four models comprehensively to find the best plan.

(1) Restriction of sedimentation

Assume that the sediment in each dam can be considered as a cone. In view of the amount of time to build a series of small dams is much less than to restore the dam, the cost of the third solution is comparatively lower than the other two.

$$
\min \sum_{1}^{n} W_{i}=\min \sum_{i}^{n} R_{p} \cdot\left[1-\left(\frac{A_{i}}{\frac{P_{i}}{\tan a} \cdot d}\right)^{n}\right]
$$

Where $W$ means the amount of sedimentation in T years; $A_{1}$ represents $4 / 3$ times the wetted crosssectional area at peak flow; $R_{p}$ is the amount of sediment transportation and $n$ means index, when 
river gradient is $1 \% \sim 0.1 \%$ and $n=0.5 \sim 0.3$; $P$ represents vertical distance between two adjoining and $d$ is steamway width.

(2) Restriction of generated power amount

Refer A as output coefficient, its value is defined as the following figure.

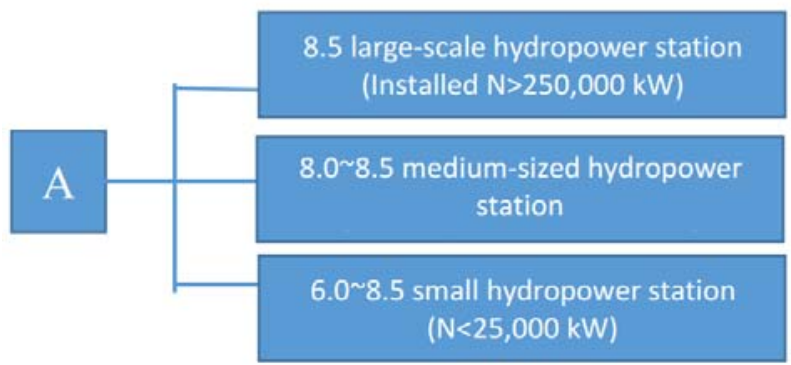

Figure 1: The flow chart $^{[3]}$

By analyzing the data since the completion of the Kariba Dam, the numerical values of the variables can be figured out: Qe=0.216Q; V=1906Q.

$$
\max \sum_{1}^{n} N_{i}=\max \sum_{1}^{n} \frac{\left(P_{i}-\frac{\mathrm{L}}{2 \cdot \tan \theta}\right) \times A \times H_{j} \times d \times L}{8825.23}
$$

Where $N$ represents power generation of hydropower station; $H_{j}$ is average water head; $Q_{e}$ means the amount of flow used to generate power.

(3) Restriction of construction cost

According to the nature of cost, the cost is divided into ecological cost and construction cost. The total installed capacity of the dams in the Tenth Five-Year Plan period is 14,950,000 kW. The average cost is $1,168.832$ USD per $\mathrm{kW}$. With the formula

$$
\min \sum_{1}^{n} 0.028 \times \frac{1}{2} \times P_{i} \times L \times d+2,275,000,000
$$

The total construction cost can be calculated. According to the request, the new dams should generate more power the existing Kariba Dam. The total installed capacity of the Kariba Dam is $195,000,000 \mathrm{~kW}$. So the construction cost is 2,275,000,000 USD.

(4) Restriction of regulating storage capacity

The larger the regulating capacity of the dams is, the better the system is. Therefore the capacity is

$$
\max \sum_{1}^{n} V_{i}=\max \sum_{1}^{n}\left(L \cdot\left(2 \cdot P_{i}-\frac{L}{\tan \theta}\right) \cdot \frac{d}{2}\right)
$$

\section{Analysis and Modeling}

\section{Case 1 (Flood period)}

The Kariba Dam has a control gate, so when replacing it with a series of small dams the flood protecting ability of the new system should be considered. The design of the flood water level is higher than the check flood level. The limit water level for flood control refers to the upper limit of water level allowed by the reservoir in flood season. In order to reduce the extra flood control capacity, set the limit water level of flood control under normal water level. Then design the flood storage capacity. 


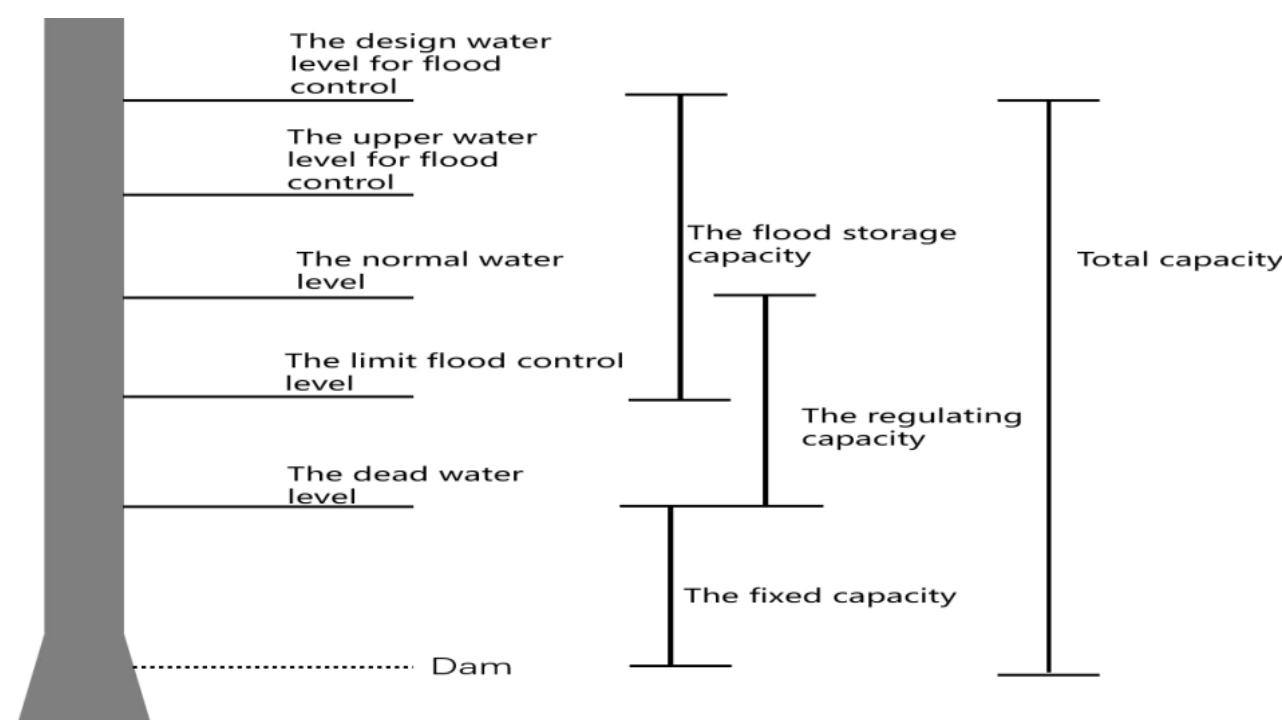

Figure 2: All water levels

Calculate the flood storage capacity by graphic method: Build right-angle coordinate. Time is Xaxis, Q/q is y-axis. Define q as the outflow, qs as the safe outflow and qx as outflow under limit flood control level.

- $\mathrm{qs}<\mathrm{qx}$

Design flood coming, t1 t2, $\mathrm{Q}$ increases, and then gradually open the gate. In order to make $\mathrm{q}=\mathrm{Q}$, the water level in the reservoir does not change;

$\mathrm{t} 1 \sim \mathrm{t} 2, \mathrm{Q}>\mathrm{qs}$, to ensure security the downstream gate will close gradually, control the discharge of $\mathrm{q}=\mathrm{qs}$. The water level continued to rise, and after the B point drawdown $\mathrm{AB}$ is the upper flood storage capacity.

- $\mathrm{qs}>\mathrm{qx}$ or qs $=\mathrm{qx}$

Design flood coming, $\mathrm{t} 0 \sim \mathrm{t} 1, \mathrm{Q}$ increases, then the gate will open gradually, so that the $\mathrm{q}=\mathrm{Q}$. The water level in the reservoir unchanged;

At $\mathrm{t} 1, \mathrm{q}=\mathrm{qx}$, the gate is open; $\mathrm{t} 1 \sim \mathrm{t} 2, \mathrm{Q}>\mathrm{q}$, reservoir water level rise, the 2 moment, $\mathrm{q}=\mathrm{qs}$;

$\mathrm{t} 2 \sim \mathrm{t} 3, \mathrm{q}>\mathrm{qs}$, in order to ensure the safety of the downstream flood control so that the gate is gradually closed, control q= qs (reservoir water level). Gradually increased, after the $\mathrm{C}$ point drawdown, $\mathrm{a} \sim \mathrm{b} \sim \mathrm{c}$ segment is part of flood storage capacity.
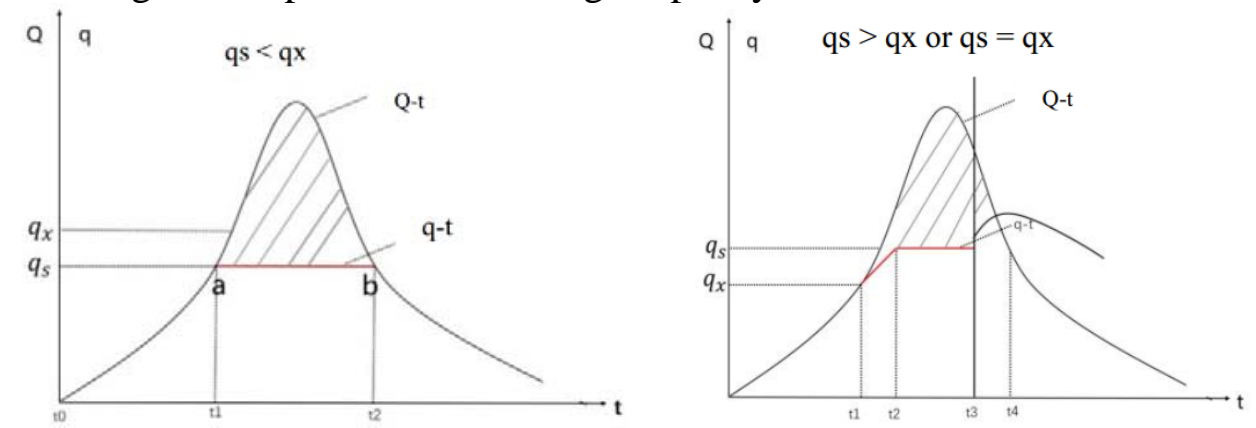

Figure 3 Outflow of the river

In order to ensure the safety of the dam itself, all of the gates should be opened to carry out the full drainage when the water level of the reservoir reaches the design flood level, and no longer consider the downstream flood control safety, which can be divided into two cases:

- $\mathrm{qs}<\mathrm{qx}$

The 2 time, the reservoir water level reached the design flood level, while Q is still large; the flood over the downstream flood control design standard, no longer consider that the safety of downstream flood control gates will be fully open to the flood, the formation of free flow, q > qs.

The 3 time, the reservoir water level reached the design flood level, while Q is still large; the flood over the downstream flood control design standard, and no longer consider that the safety of downstream flood control gates will be fully open to the flood, the formation of free flow, $q>q s$.

- $\mathrm{qs}>\mathrm{qx}$ or qs $=\mathrm{qx}$ 

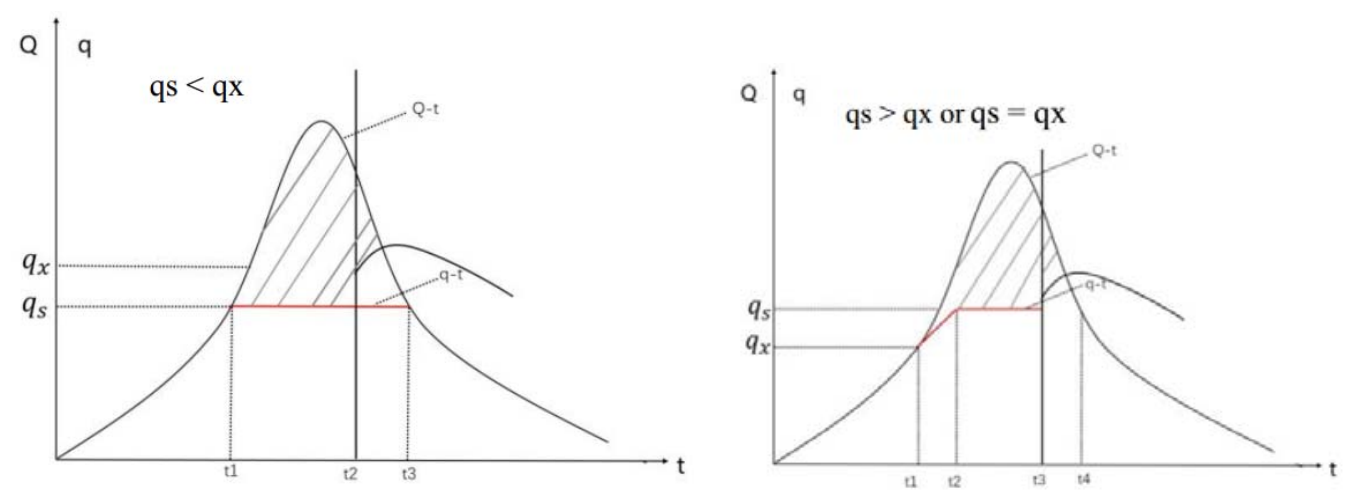

Figure 4 Outflow of the river (neglect the downstream flood control safety)

The model is extended to the dam system at the same time: when the flood comes, the control flow of each dam satisfies the above model, the total flood control capacity is

$$
V=\sum V_{i}
$$

\section{Case 2 (drought period)}

Because of the downstream reason, upstream flood peak appeared in the 2 3 month, the middle peak appeared in 4 5 months, while the downstream peak flow effect is generally not too large, about 85003 for 5 weeks ${ }^{[4]}$. The graphic method drawing the corresponding required flood storage capacity, further analyzes the impact of basin area of flood period about $42 \mathrm{w}^{2}$, which mainly distributed in the upper reaches of meeting places. The impact time is about 10 days in May 14 day, the most harmful effects of location information in the shadow, shown in figure5.
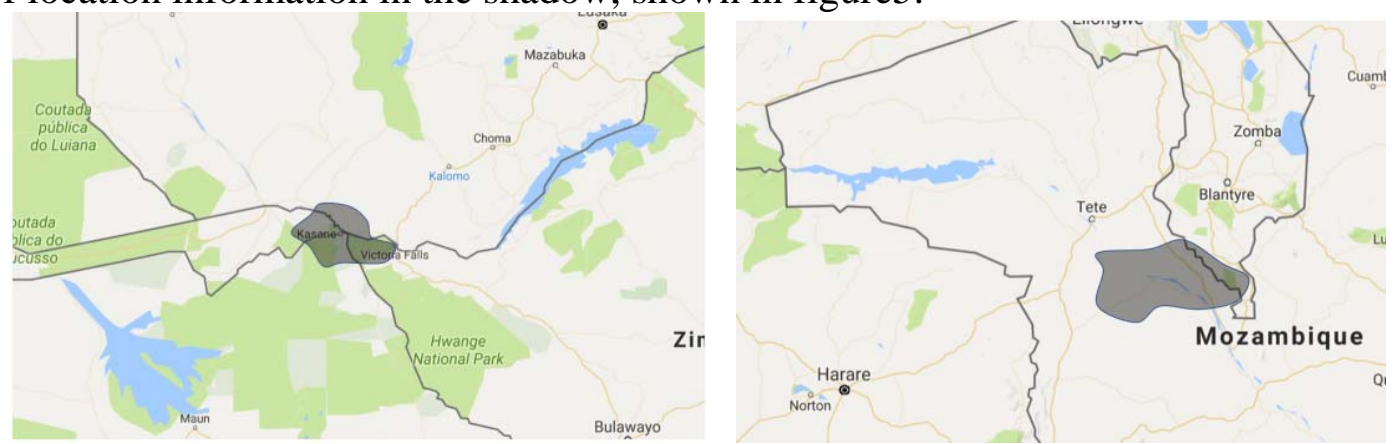

Figure 5 and figure 6 The most harmful effects of location

The dry period is generally $4 \sim 5$ months and the water flow in flood period is less than $10 \%$. Moreover, the main effect analysis method is the same. In the middle and lower position of the Zambezi River downstream to the site, at the end of November, the most harmful effects of location information are in the shadow, shown in figure 6.

According to the Google Map and the existing Karila Dam, the rever width $\mathrm{d}$ is $153 \mathrm{~m}$ and the number of the small dams should be between 10 and 20. Then the height difference between normal and dead water level is $7 \mathrm{~m}$, and $\tan \theta=1 / 2500 . \mathrm{Hj}=50 ; \mathrm{A}=8.5$.

According to the data above, $\mathrm{Rp}=4 \times 109 ; \mathrm{A} 1=\mathrm{Hj} * \mathrm{~d}=7650 ; \mathrm{n}=0.3$.

The optimum number of the small dams is 13 by using genetic algorithm. As for the specific location of each dam, the data and figure below make it clear. 
Table 1 Value of distance

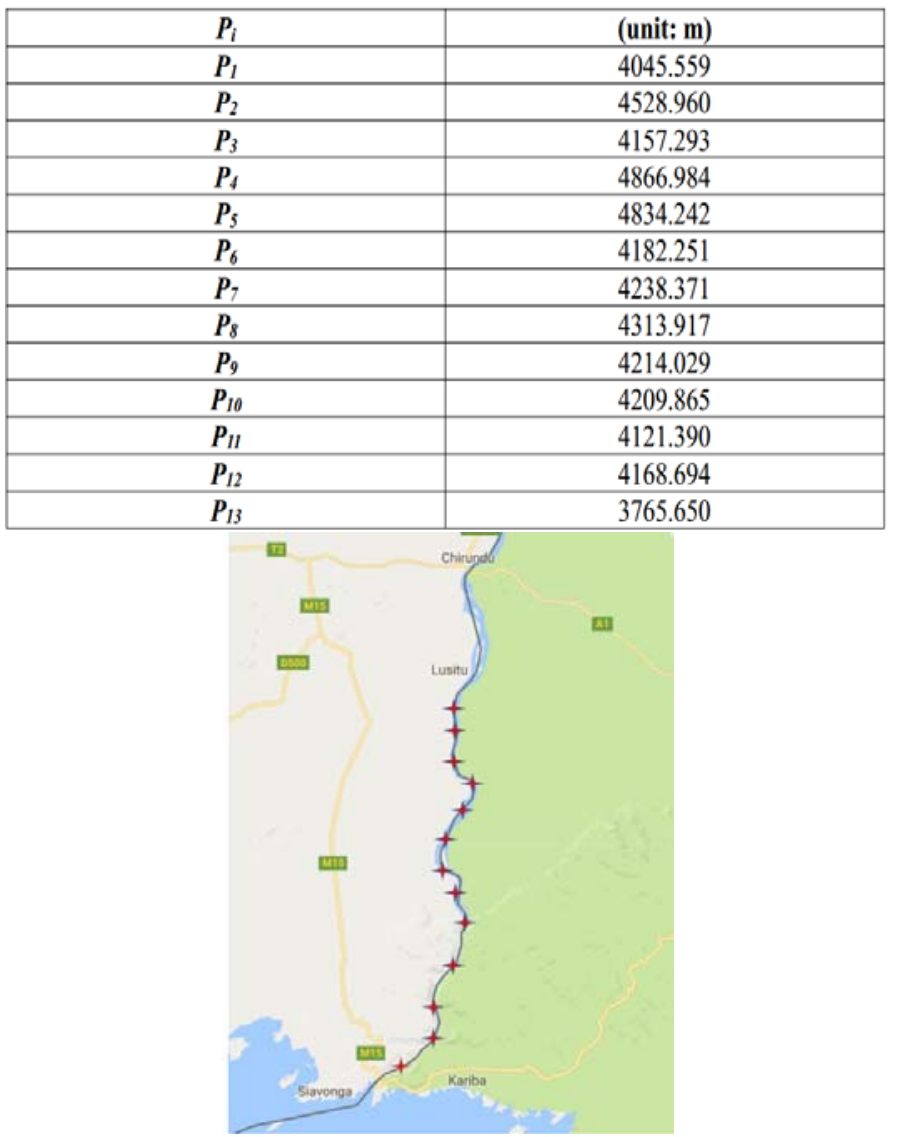

Figure 7 Location of each dam

\section{Conclusion}

In view of the amount of time to build the series of small dams is much less than to restore the existing dam, so the cost of the third solution is comparatively lower. The optimum plan of the third solution is figured out to build 13 small dams. The specific location of each dam is shown in the graph above. The solution to flood period can be obtained with the model of regulating storage capacity. The main effect analysis method ibid, position in the middle and lower reaches of the Zambezi River downstream to the site are promising to be applied to practical engineering.

\section{References}

[1] The Ministry of Water Resources of the PRC. Statistical bulletin of Water and Sands of Chinese River. http://www.hydroinfo.gov.cn/,2003.

[2] Zhang Z J, Zhang S B \& Feng TH. Calculation of flood control benefit for economic postevaluation for Taolinkou Reservoir Project. China Rural Water and Hydropower, 2002.

[3] http://wenku.baidu.com/link?url=8HXoeA4l4H-RxCzIWa8VzNoZIaWwhcRQ0RYgPZUPXIMlMZHI5kbrEteimlAk6y_O2xP9NSPm6b4lfyqDsLpG _NHw-d11rfcrmeDFW4Pwxq

[4] http://baike.baidu.com/link?url=zVR7259BXmrruZZ1mnBIQSxNTu9AX0M2Zsi3z1thleGkMl eQAt78b0QCAGGC_UnY7qAeCaTMs1P8ggeUP0NGpoLFPIN2RyRrv8hzMbi_57KDmo2Ksq7PyaMLOe-Hbg5 